\title{
Voltage regulation and phase quantity increase of two high- power 12-phase rectifiers
}

Valery Safonov, Mikhail Dziuba

Departement of Electric Power Generation and Supply, South Ural State University (national research university), Rusia.

\begin{tabular}{l}
\hline \hline Article Info \\
\hline Article history: \\
Received Apr 17, 2019 \\
Revised Jul 22, 2019 \\
Accepted Aug 3, 2019 \\
\hline
\end{tabular}

\section{Keywords:}

12-phase high-power rectifier booster transformer self-excited voltage inverters voltage regulation under load

\begin{abstract}
In this article, we present a new method of simultaneously increasing the phase quantity and regulating the rectified voltage for two 12-phase highpower rectifiers operating at a common load. Self-excited voltage inverters separately form the necessary voltages for voltage regulation and for increasing the phase quantity. The formed voltage is input with the help of a common booster transformer. Separating the inverters functions and using the common booster transformer makes it possible to reduce the installed power of the equipment significantly compared to similar circuits when the regulation range of the rectified voltage is up to $5 \%$. Calculations show that the inverter power for increasing the phase quantity is about $3 \%$ of the rectifier power. The circuit was modeled in MatLab/Simulink and the electromagnetic processes in the rectifier were studied. The proposed method makes it possible to reduce the total harmonic distortion of the network current and the pulsation coefficient of the rectified voltage to the values typical for 24-phase rectifiers.
\end{abstract}

Copyright (C) 2019 Institute of Advanced Engineering and Science. All rights reserved.

\section{Corresponding Author:}

Mikhail Dziuba,

Departement of Electric Power Generation and Supply,

South Ural State University(national research university),

76Lenin prospekt, Chelyabinsk, Russia.

Email: dziubama@susu.ru

\section{INTRODUCTION}

Energy indicators at the point of common coupling (PCC) of powerful rectifiers and the possibility of regulating (stabilizing) the magnitude of the rectified voltage are very important for electrical equipment with rectifiers. Various methods are used to regulate the magnitude of the voltage, such as step regulation of the voltage of the transformers under load, saturable reactor, etc. [1,2]. The most promising method is to use self-excited voltage inverters with a DC link [3-5]. Compensated rectifiers and circuits with a large number of phases are used to improve the energy indicators at PCC [6-11]. Active filters connected in series and parallel at the different points of rectifier circuits $[12,13]$ are also used for this purpose.

Separate technical equipment is used to regulate the rectified voltage $[6,8]$ and improve the energy indicators [6], [14-16]. An increase of the total installed capacity of the equipment leads to an increase in cost, weight and size of the equipment. The problem is to ensure the required power quality and the voltage regulation range while reducing the installed capacity of the equipment.

Circuits for phase splitting with autotransformers $[7,17,18]$ allow us to maintain the voltage quality at the PCC within the standard values (IEC 61000). The installed capacity of transformer equipment in such schemes is small, but they do not have a galvanic isolation, which is mandatory for high-power circuits. In addition, either additional transformer equipment or a voltage regulator is needed to regulate the voltage magnitude in high-power circuits.

A special regulating transformer and a passive filter connected to it [10] is used to regulate the rectified voltage and reduce the total harmonic distortion (THD) of the voltage at the PCC. This scheme 
provides the required level of the power quality in all operating modes. However, this transformer is chosen at a full power transferred to the load, which leads to additional energy losses and an increase in the installed capacity of the equipment.

Circuits with a converter with a DC link and with DC direct-current buses for regulating the rectified voltage of 12-phase and 24-phase rectifiers were studied in articles [6]. The power of such filters is limited by technical and economic factors because of the existing elemental base of power electronics. Therefore, the range of voltage regulation for high-power rectifiers is limited only by voltage regulation within a single stage of the tap-changer transformer. Booster transformers are used to improve the energy indicators [19]. This solution is the most effective, since the installed capacity of transformer equipment is reduced.

In $[20,21]$, a scheme was suggested for increasing the phase quantity of two 12-phase rectifiers with a total load up to the 24-phase regime. The scheme makes it possible to improve energy parameters and voltage regulation and is effective for a large range of voltage regulation (more than $25 \%$ of the nominal value). However, if voltage regulation is not required, transformer equipment and converters with a power of about $13 \%$ of the rectifier power are needed to increase the phase quantity.

This paper presents a scheme with the booster transformers similar to those considered in [19] and an original arrangement of self-excited voltage inverters. Due to this, the installed capacity of the equipment was reduced while maintaining the quality of electrical energy at the PCC and the control range of the rectified voltage.

\section{CIRCUIT DESCRIPTION}

A circuit of two 12-phase rectifiers with a common load and a device for regulating the rectified voltage magnitude and increasing the rectifier phase quantity are shown in Figure 1. Self-excited voltage inverters SVI1 and SVI2 regulate the voltage and pass on the necessary active power from the power network or rectifier buses through the converter. SVI3 increases the phase quantity of the two 12-phase rectifier up to the mode of a 24-phase rectifier. If the inverter elements are ideal, then SVI3 does not consume active power and can work with a capacitive energy accumulator. Booster transformers with a special design input the voltages $\mathrm{dE} 1$ and $\mathrm{dE} 2$, formed by SVI1-SVI3 and LC-filters F1-F3, into the switching circuits. The winding ends of the booster transformers in Figures 1 and 2 have the same designation.

More detailed schemes of booster transformers T1 shown in Figure 2(a) and T2 shown in Figure2(b) used are shown in Figure 2. The ends of windings with number of the winding turns w, w1 and w2 respectively are indicated by the symbol "*". The inputs $(\mathrm{A} 1, \mathrm{~B} 1, \mathrm{C} 1)$ of the primary windings of the booster transformers are connected to the high voltage inputs of the power transformers. The inputs (A, B, C) are connected to the power network, the outputs $(\mathrm{a} 1, \mathrm{~b} 1, \mathrm{c} 1)$ are connected to the SVI3 converter, which increases the phase quantity, and the outputs $(a, b, c)$ are connected to SVI1 and SVI2, which regulates the voltage.

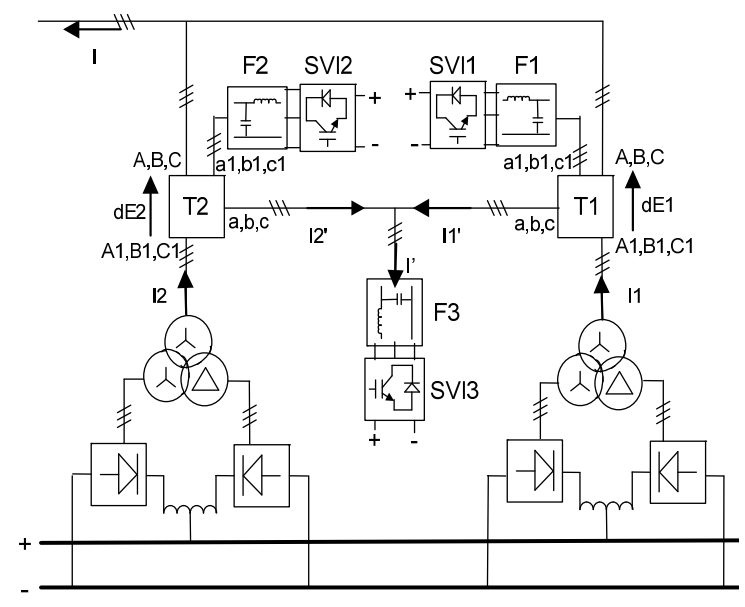

Figure 1. The circuit of two12-phase rectifierswith a common load 


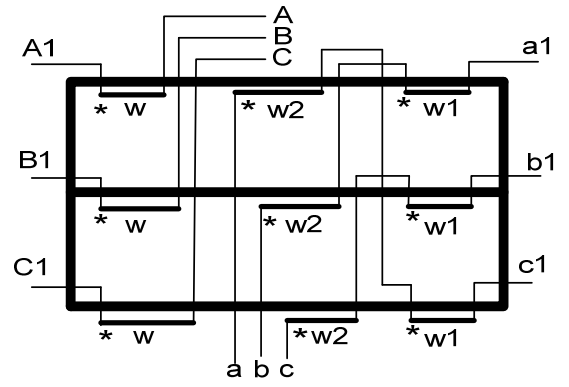

(a)

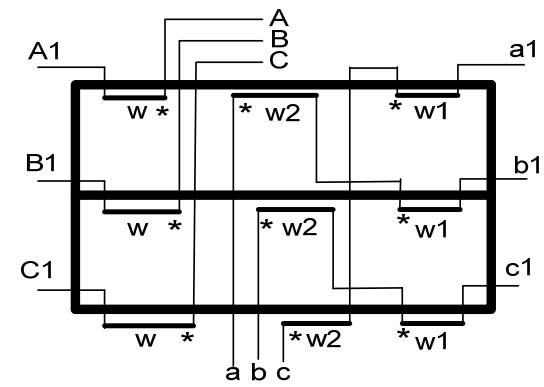

(b)

Figure 2. Detailed schematic of booster transformers T1 and T2

The secondary windings of booster transformers T1 and T2 are connected in such way as to provide a phase shift of the first harmonic of the current by +7.5 and -7.5 degrees, respectively. For this, the number of winding turns must satisfy the relation.

$$
w_{2}=\frac{w_{1} \sin \left(7.5^{\circ}\right)}{\sin \left(112.5^{\circ}\right)}
$$

The variant of the booster transformers $\mathrm{T} 1$ and T2 shown in Figure 2 is not the only one possible. It is important that the first harmonics of the secondary windings currents of the booster transformers are opposite in phase when SVI3 is operating.

\section{MATHEMATICAL MODEL}

In this section, it is explained the results of research and at the same time is given the comprehensive discussion. Results can be presented in Figures, graphs, tables and others that make the reader understand easily $[2,5]$. The discussion can be made in several sub-chapters.

When assessing the installed capacity of additional transformer equipment in the circuit shown in Figure 1, the installed capacities of booster transformers were taken into account. The calculations are made in accordance with [22].

The dependence of the booster transformer power on the regulation magnitudea $=U_{R} / U_{F}\left(U_{R}-\right.$ added voltage, $\mathrm{U}_{\mathrm{F}}$ - phase to ground voltage of the grid) is

$$
S(a)=\frac{S_{1}(a)+S_{2}^{\prime}(a)+S_{2}^{\prime \prime}(a)}{2}
$$

The installed powers are equal to. $S_{1}(a)=d E_{1}(a) I_{1}, S_{2}^{\prime}(a)=d E_{1}^{\prime}(a) I_{1}^{\prime}, S_{2}^{\prime \prime}(a)=d E_{1}^{\prime \prime}(a) I_{1}^{\prime \prime}$ for one of the phases of the primary winding and the components of the secondary winding of booster transformer respectively. The currents of the windings are determined by the load and are equal toI ${ }_{1}^{\prime}=\mathrm{I}_{1} \mathrm{~K}_{\mathrm{T}}$, where $\mathrm{I}_{1}-$ phase current shown in Figure 1 andK $\mathrm{K}_{\mathrm{T}}$ - transformation ratio. The voltage of the primary winding is created by the SVI3 converter to increase the phase quantityI' $=\mathrm{U}_{\mathrm{F}} \sin \left(7.5^{\circ}\right)$ and one of the SVI1 or SVI2 converters to control the voltageU" $(\mathrm{a})=\mathrm{aU}_{\mathrm{F}}$. The phase shift between these components of the voltage is 90 e. degrees, hence the winding voltage is

$$
d E_{1}(a)=U_{F} \sqrt{\sin \left(7.5^{\circ}\right)^{2}+a^{2}}
$$

The winding voltages of secondary winding parts shown in Figuer 2 are equal

$$
U_{2}^{\prime}(a)=\frac{\sin \left(112.5^{\circ}\right)}{\sin \left(60^{\circ}\right)} \frac{U_{V 1}(a)}{K_{T}}, U_{2}^{\prime \prime}(a)=\frac{\sin \left(7.5^{\circ}\right)}{\sin \left(60^{\circ}\right)} \frac{U_{V 1}(a)}{K_{T}}
$$

When performing the calculations, it was assumed that the phase shift between phase current and voltage is 15 el. degrees and the rectifier power is equalP $P_{d}=6 U_{F} I_{F} \cos \left(15^{\circ}\right)$. Taking into account (2-4), we get the relative (normalized to the rectifier power) installed capacity of two three-phase booster transformers in the form

Int J Pow Elec \& Dri Syst, Vol. 10, No. 3, Sep 2019 : 1454 - 1460 


$$
S^{\prime}(a)=\frac{6 S_{V}(a)}{P_{d}}=\frac{\sqrt{\sin \left(7.5^{\circ}\right)^{2}+a^{2}}\left(1+\frac{\sin \left(112.5^{\circ}\right)+\sin \left(7.5^{\circ}\right)}{\sin \left(60^{\circ}\right)}\right)}{2 \cos \left(15^{\circ}\right)} .
$$

To estimate the installed power of converters SVI1, SVI2, and SVI3, it was assumed that the converters were replaced by ideal voltage sources. For one of the phases of the converter SVI3 installed power is.

$$
S_{3 P}(a)=\frac{U_{F} \sin \left(7.5^{\circ}\right)}{K_{T}} 2 K_{T} \sqrt{\frac{I_{1}^{2}}{11^{2}}+} \frac{I_{1}^{2}}{13^{2}}
$$

The calculation used the ratioI $_{(\mathrm{n})}=\mathrm{I}_{(1)} / \mathrm{n}$ for the harmonics of the network current for a threephase bridge circuit in which the switching processes were not taken into account. It was also taken into account that the currents of the 11th and 13th harmonics are larger than the other harmonics in SVI3. For one phase of the SVI1 and SVI2 converters, the installed capacity is

$$
S_{1 P}(a)=S_{2 P}(a)=\frac{U_{F} a}{K_{T} \cos \left(30^{\circ}\right)} K_{T} I_{1}
$$

Taking into account (5-6), we get the relative (normalized to the rectifier power) installed capacity of three-phase converters SVI1, SVI2, and SVI3 in the form

$$
S^{\prime}(a)=\frac{\frac{a}{\cos \left(30^{\circ}\right)}+\sin \left(7.5^{\circ}\right) \sqrt{\left(\frac{1}{11}\right)^{2}+\left(\frac{1}{13}\right)^{2}}}{\cos \left(15^{\circ}\right)}
$$

Calculations of the installed power of the transformer equipment and the installed power of the converters for an alternative circuit [23] are made in the same way. In each case, the dependence is determined by the expression

$$
S^{\prime \prime}(a)=\frac{\sqrt{\sin \left(7.5^{\circ}\right)^{2}+a^{2}}}{\cos \left(15^{\circ}\right)}
$$

The dependences $(5,9)$ of the booster transformers power on the voltage regulation depth $\mathrm{k}$ a for a circuit with a general voltage regulation and phase quantity increase (red) [23] and for a circuit with separate converters for phase quantity increase and for voltage regulation (blue) are shown in Figure 3(a). Similar dependences $(8,9)$ for the total converters power are shown in Figure 3(b).

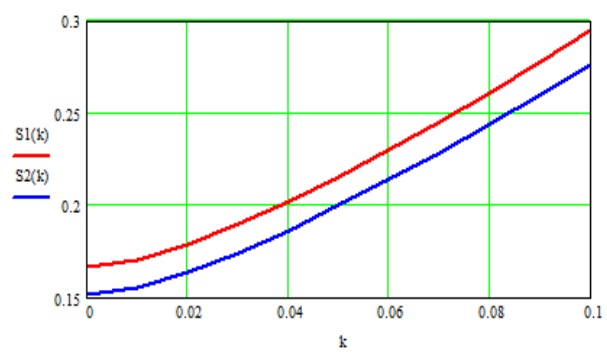

(a)

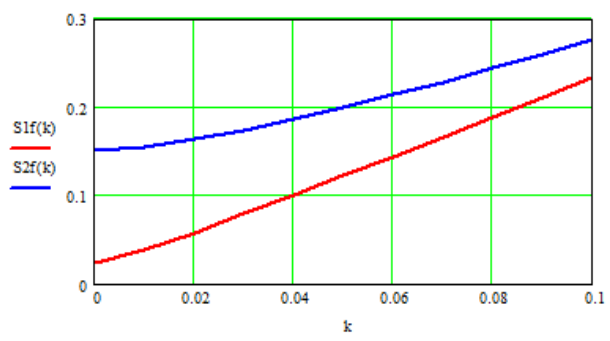

(b)

Figure 3. The dependence of the booster transformers power (a) and the converter power (b)

Taking into account the assumptions made above, the external characteristics for the considered scheme are calculated in the standard way [22] and have the form

$$
U_{d}\left(I_{d}\right)=U_{d 0}+a U_{F}+x I_{d}
$$

where $U_{\mathrm{d} 0}-$ rectified voltage in idle mode without regulation, $\mathrm{I}_{\mathrm{d}}-$ rectified current, andx - switching circuit resistance. 


\section{SIMULATION MODELING}

To model the power supply system, we used a three-winding converter transformer with windings voltage of $10 \mathrm{kV}$ and $620 \mathrm{~V}$, power of $10 \mathrm{MW}$, a short-circuit of voltage $8.4 \%$ and short-circuit power $83 \mathrm{~kW}$. The frequency of power supply is $50 \mathrm{~Hz}$. The grid resistance is about $12 \%$ of the resistance of the switching circuit. The load power was assumed to be $19 \mathrm{MW}$. Thus, the load current is $20 \mathrm{kA}$, and the rectified voltage in the idle mode is $950 \mathrm{~V}$. The inductance of the equalizing reactors was assumed to be 6.6 $\mathrm{mH}$, which ensures that there is no pulsation of the rectified current. At the given load, the duration of the switching process is about 15 e. degrees. The chosen parameters of the model are typical for power supply systems for electrolysis plants. It was assumed that the booster transformers and diodes were ideal. The conversion factor for the booster transformer is 3 .

The modulation frequency of the self-excited voltage inverters was $1000 \mathrm{~Hz}$. The parameters of the input L-shaped filters were equal for SVI1, SVI2, and SVI3 L1 $=\mathrm{L} 2=\mathrm{L} 3=0.1 \mathrm{mH}$ and C1 $=\mathrm{C} 2=2000 \mathrm{mF}$, $\mathrm{C} 3=500 \mathrm{mF}$ respectively. This ensured the transmission ratio at the fundamental harmonic $\mathrm{K} 1=\mathrm{K} 2=0.987$, $\mathrm{K} 3=1.005$, at the modulation frequency $1 \mathrm{kHz}$, the frequency of the consecutive resonance of the input resistance in the idle mode $\mathrm{fl}=\mathrm{f} 2=356 \mathrm{~Hz}, \mathrm{f} 3=712 \mathrm{~Hz}$, and THD of the voltage at the filter entrance $\mathrm{KTHD} 1=\mathrm{KTHD} 2=4.67 \%, \mathrm{KTHD} 3=42.96 \%$.

Simulation of the power supply system with the above parameters was performed in MatLab/Simulink.

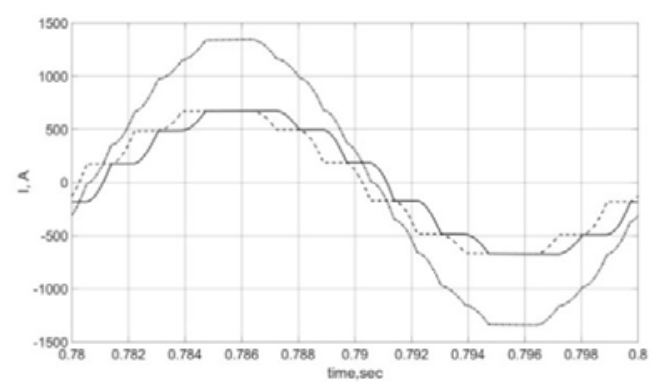

(a)

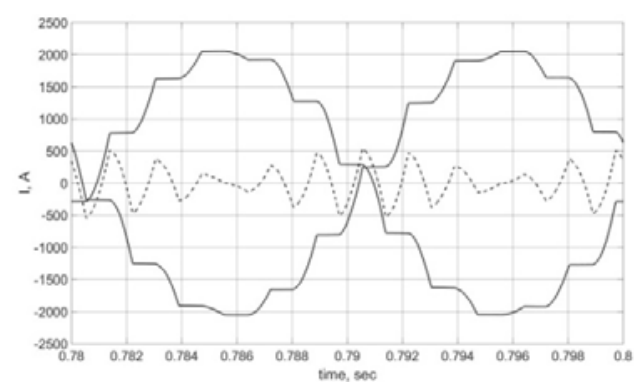

(b)

Figure 4. The time dependences of currents

The time dependences of currents I1 and I2 shown in Figure 1 for one phase of the 12-phase rectifier (dashed line, solid line) and the network current I (dash-dotted line) are shown in Figure 4(a). SVI3 provides an additional input voltage to each of the 12-phase rectifier such that the diodes switching processes of one of the rectifiers are shifted relative to the processes in the other rectifier by $1 / 24$ of the network voltage period. Harmonic analysis of these currents shows that THD is $7.8 \%$ for the currents I1 and I2 and is $1.4 \%$ for the current I. The 11th and 13th current harmonics remain in the network current I, but their magnitude is significantly reduced when SVI3 is operating.

The currents I1' and I2' of the secondary windings of the booster transformers (solid lines) and the input current I' of the SVI3 (dashed line) are shown in Figure 4(b). Harmonic analysis of these currents shows that the currents I1' and I2' of the windings are opposite in phase and the input current I' contains only the 11th and 13th harmonic.

The rectified voltage, constructed at phase shift between the input voltages of the power transformers, equal to 4 degrees (dashed line) and 15 e. degrees (solid line) is shown in Figure 5. Spectral analysis of the dependences shows that in the rectified voltage, when the phase quantity of the rectifier increases, the 12th harmonic remains, gradually decreasing in magnitude.

\section{RESULTS AND DISCUSSION}

The transformer equipment power in the considered case is somewhat higher due to construction of the booster transformer. The total power of the converters is much lower. If there is no need for voltage regulation in the circuit, an increase of phase quantity is achieved by a converter whose power is $3 \%$ of the rectifier's power, versus $13 \%$ in the alternative version [23]. This is because in the proposed construction, the current of the first harmonic does not flow in the converter. When the depth of voltage regulation increases, this ratio is reduced, but in any case the scheme under consideration remains more profitable.

Int J Pow Elec \& Dri Syst, Vol. 10, No. 3, Sep 2019 : 1454 - 1460 


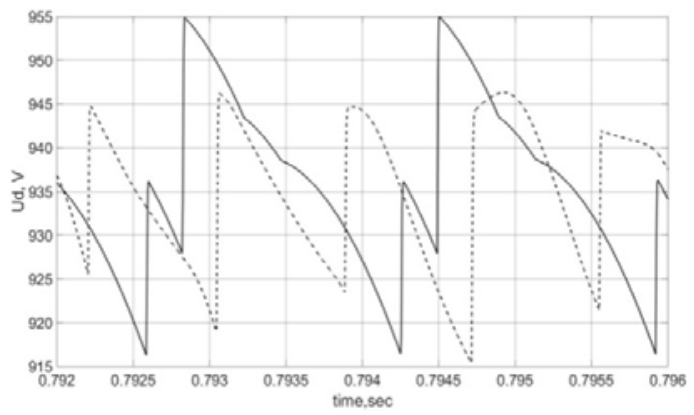

Figure 5. The time dependences of rectified voltage

The results obtained in the simulation are consistent with the results of [22] in multiphase circuits both in the network current curve and in the rectified voltage curve. The rectified voltage curve shown in Figure 5 does not fully coincide with the classical curve of the 24-phase rectifier. However, the difference in the ripple coefficient between them is insignificant.

A harmonic analysis of these currents shows that the THD is $7.8 \%$ for the currents I1 and I2, and $1.4 \%$ for the current I. A small inductance of the switching circuit and short switching time of diodes are typical for rectifiers at low voltages and power. Thus, the THD of the grid current is 5.04\% in [7]. The similar coefficient is equal to $0.78 \%$ in [10], where the classical 24-phase rectification mode is simulated. The increase in the THD of the grid current in the considered scheme with respect to the value in [10] indicates that the 11th and 13th harmonics in the network current curve are not completely eliminated in the scheme shown in Figure 1. A general analysis of the obtained curves shows that the rectifier operation mode is close to the operation of a 24-phase rectifier.

The proposed scheme shown in Figure 1 makes it possible to increase the phase quantity and to regulate the output voltage of the rectifier, consisting of two powerful 12-phase rectifiers operating at a common load. In this scheme, separate inverters and common transformer equipment increase the phase quantity and regulate the voltage.

\section{CONCLUSION}

In the considered scheme shown in Figure 1, serial, wide-spread three-winding transformers and rectifier bridges are used as a 12-phase rectifier. This allows us to apply the proposed solution on the already installed 12-phase rectifier. Thus, it is possible to improve the quality of electricity without replacing the main process equipment, which provides significant financial savings.

The proposed scheme makes it possible to reduce the total power of inverters in comparison with a scheme in which these functions are performed by a common inverter. Total power is reduced from $20 \%$ to $13 \%$ with a regulation range of $5 \%$ of the rectified voltage.

Using simulation in MATLAB/Simulink, we have shown that the electromagnetic processes in the proposed scheme are close to the mode of a 24-phase rectifier in relation to both grid and load.

\section{REFERENCES}

[1] H. Xu, et al., "Coordinate Control Strategy for Current Stabilization in an Aluminum Smelter Including on Load Tap Changer," Energy and Power Engineering, vol. 5, pp. 1410-1414, 2013.

[2] C. A. Mahrez and G. de Préville, "Global current regulation and Ah compensation for aluminum electrolysis substation," 2015 17th European Conference on Power Electronics and Applications (EPE'15 ECCE-Europe), pp. $1-8,2015$.

[3] T. H. Nguyen, et al., "A Series-Connected Topology of a Diode Rectifier and a Voltage-Source Converter for an HVDC Transmission System," IEEE Transactions on Power Electronics, vol. 29, pp. 1579-1584, April 2014.

[4] M. Makoschitz, et al., "Control Concepts for Hybrid Rectifiers Utilizing a Flying Converter Cell Active Current Injection Unit," IEEE Transactions on Power Electronics, vol. 32, pp. 2584-2595, April 2017.

[5] Y. I. Khokhlov, et al., "Electromagnetic Processesin Power Transformerswith Vector Control," Journal Russian Electrical Engineering, vol. 87, pp. 45-49, 2016.

[6] Y. I. Khokhlov, et al., "Output and power performances of twelve-phase compensated rectifier swith vector control," Bulletin of the South Ural State University Series "Power Engineering, vol. 14, pp. 37-45, 2014.

[7] X. Q. Chen, et al., "Thirty-Six Pulse Rectifier Scheme Based on Zigzag Auto-Connected Transformer," Archives of Electrical Engineering, vol. 65, pp. 117-132, March 2016.

Voltage regulation and phase quantity increase of two high-power 12-phase rectifiers (Valery Safonov) 
[8] X. G. Ma, et al., "The Voltage Output Characteristics of New 24-Pulse Rectification System under Unbalanced Source Voltage," in Materials Science and Information Technology, Pts 1-8, pp. 3820-3825, 2012.

[9] S. Fukuda, et al., "An Auxiliary-Supply-Assisted Harmonic Reduction Schemefor 12-Pulse DiodeRectifiers," IEEE Transactionson Power Electronics, vol. 23, pp. 1270-1277, May 2008.

[10] M. Al-Mahari, et al., "A New Aluminum Pot Line Rectifomer Scheme with Effective Harmonic Suppression Capability," International Journal of Power Electronics and Drive System (IJPEDS), vol. 9, no 4, pp. 1573-1583, December 2018.

[11] V. Garg, et al., "24-Pulse AC-DC Converter for Harmonic Mitigation," IET Power Electronics, vol. 2, pp. 364-374, July 2009.

[12] T. Rajesh and A. Nirmalkumar "A Shunt Active Power Filter for 12 Pulse Converter Using Source Current Detection Approach," International Journal of Power Electronics and Drive System (IJPEDS), vol. 7, pp. 225-234, 2016.

[13] H. Fujitaand, H. Akagi, "The unified power quality conditioner: The integration of series active filters and shunt active filters," PESC Record. 27th Annual IEEE Power Electronics Specialists Conference, Baveno, vol.1, pp. 494501, 1996.

[14] X. Q.Chenand H. Qiu. "Zigzag Connected Autotransformer-Based 24-Pulse AC-DCConverter," International Journal of Emerging Electric Power Systems vol. 16, pp. 23-32, February 2015.

[15] V. Sheelvant, et al., "Improve mentin Harmonic Reduction of a Zigzag Autoconnected Transformer Based 12-Pulse Diode Bridge Rectifier by Current Injectionat DC Side," IEEE Transactions on Industry Applications, vol. 53, pp. 5634-5644, 2017.

[16] F. J.Chivite-Zabalza, et al., "A 24-Pulse Voltage Sourced Converter with Passive and Active Harmonic Voltage Injection," IECON 2006 - 32nd Annual Conferenceon IEEE Industrial Electronics, Vols 1-11, pp. 2819-2824, 2006.

[17] F. J. Chivite-Zabalza, et al., "A Simple, Passive 24-Pulse AC-DC Converter with Inherent Load Balancing Using Harmonic Voltage Injection," 2005 IEEE 36th Power Electronic Specialists Conference, IEEE Power Electronics Specialists Conference Records, pp. 76-82, 2005.

[18] F. J. Chivite-Zabalza, et al., "A Simple, Passive 24-Pulse AC-DC Converter with Inherent Load Balancing," IEEE Transactions on Power Electronics, vol. 21, pp. 430-439, March 2006.

[19] Yu. I. Khokhlov, et al., "On some useful qualities of 12-phase Converter swith a controllable Ensemble of harmonics in a compensating Device common for six-phase Units," Russian Electrical Engineering, vol. 84, pp. 542-548, 2013.

[20] H. Z. Azazi, et al., "High Power Factor and Regulated Output Voltage for Three-Phase AC-DC Converter Using Single-Switch Cuk Converter," 2017 Nineteenth International Middle-East Power Systems Conference, pp. 43-51, 2017.

[21] K. Darji, et al., "Series Voltage Injection Strategy for Reactive Power Compensation of HVDC Rectifier Station," Proceedings of the First IEEE International Conference on Power Electronics, p. 4, 2016.

[22] G. S. Zinoviev, "Fundamentals of power electronics" Book. - Novosibirsk: Publisher NSTU, 1999.

[23] Yu. I. Khokhlov, et al., "Electromagnetic processes in non-compensated rectifier with the increase of stage motion vector control,"Science SUSU. Section of technical Sciences: materials of the 67th scientific conference, pp. 935941, April 2015.

\section{BIOGRAPHIES OF AUTHORS}

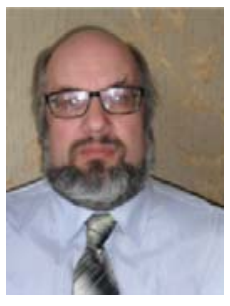

Valery I. Safonov received the E.Sc. degrees in Electrophysics from South Ural State University, Russia, in 1993. He received Ph.D. degree in Radio Physicsfrom Tomsk State University, Russia, in 1997. Currently he is an assistant professor at the Faculty Power Engineering of South Ural State University. Valery is co-author of several papers on nonlinear optics and power electronic systems.

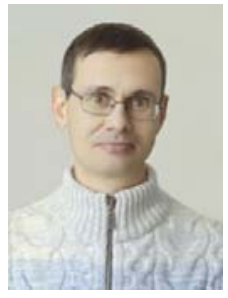

Mikhail A. Dziuba received the E.Sc. degrees in Power Engineering from South Ural State University, Russia, in 1997. He receivedPh.D. degree in Power Electronicsfrom South Ural State University, Russia, in 2005. Currently he is an assistant professor at the Faculty Power EngineeringSouth Ural State University. Mikhail has many journal and conference papers in power electronic systems. 